\title{
Correlation Between Markers of TH2-Oriented Response and SOFA Score in Sepsis
}

\author{
Lea Paola Fabbri ${ }^{*}, 1$, Veronica Santarlasci ${ }^{2}$, Maria Nucera ${ }^{1}$, Francesco Liotta ${ }^{2}$, Chiara Becchi ${ }^{1}$, \\ Lorenzo Cosmi $^{2}$, Mohamed Al Malyan ${ }^{1}$, Enrico Maggi ${ }^{2}$, Sergio Boncinelli ${ }^{1}$ and \\ Francesco Annunziato ${ }^{2}$ \\ ${ }^{I}$ Department of Medical and Surgical Critical Care, Section of Anaesthesia and Intensive Care, Florence University,
Italy
${ }^{2}$ Immunoallergology Unit of the Department of Internal Medicine, Florence University, Italy
}

\begin{abstract}
A shift from Th1- to Th2-type cell immune response has been suggested to occur during sepsis, contributing to cell-mediated immunity suppression and to poor prognosis. The aim was to study the relationship between old and new Th2 markers and the clinical outcome of sepsis. 30 critically ill patients with sepsis for $\geq 48$ hours were enrolled in a prospective clinical study. Blood samples were collected at the enrolment, at the $5^{\text {th }}$ and $10^{\text {th }}$ day. Serum levels of total IgE and soluble chemokines related to Th1- and Th2 responses were evaluated. The percentages and absolute number of CD4+ and CD8+Tcells as well as CRTH2+Tcell subsets were detected by flow cytometry. Sepsis severity was assessed with SOFA score. The mean values of total $\operatorname{IgE}$ in septic patients were significantly higher than in $\operatorname{controls}(\mathrm{p}<0.01)$. Moreover, IgE levels of septic patients who died were higher than those of survived patients $(\mathrm{p}<0.05)$. It has been found that IgE levels directly and RANTES inversely correlated with SOFA score at different time points $(\mathrm{p}<0.01)$. A significant correlation between the percentages of $\mathrm{CRTH} 2+/ \mathrm{CD} 4+($ but not $\mathrm{CRTH} 2+/ \mathrm{CD} 8+) \mathrm{T}$ cells and SOFA at different time points was observed $(\mathrm{p}<0.05)$. The direct correlation between total IgE, the percentages of circulating CRTh2+CD4+T cells and the clinical outcome suggests that clinical worsening of sepsis is closely linked to the shift towards a predominant less protective Th2 phenotype. Although these are preliminary results, the longitudinal analysis of these parameters during the disease could be proposed as useful prognostic tools in sepsis.
\end{abstract}

\section{INTRODUCTION}

Severe sepsis remains to be a major problem in Intensive Care Units (ICU) with a poor outcome and a mortality rate as high as $30-40 \%$ [1]. Despite significant improvement in supportive measures, incidence of severe sepsis continues to rise by $1.5 \%$ to $8 \%$ each year [2].

The release of inflammatory mediators like cytokines, lipid mediators and reactive oxygen species generates a widespread activation of cells responsive to pathogens resulting in uncontrolled systemic inflammation $[3,4]$. The control over the systemic inflammation is basically a role played by both innate and adaptive immunity. In particular, Toll-like receptors on Antigen Presenting Cells (APC) are triggered by surface components of pathogenic agents to release a panel of cytokines essential for the development of $\mathrm{T}$ effector cell subsets, conditioning the efficacy of protection against pathogens. The activated effector $T$ cells are essentially programmed to secrete cytokines with one of two distinct and antagonistic profiles. They either produce cytokines with pro-inflammatory activity (type 1 helper T cells Th1- such as IFN-g) or cytokines with anti- inflammatory (type 2 helper T cells -Th2- such as IL-4, IL-13, IL-5) or

\footnotetext{
*Address correspondence to this author at the Department of Medical and Surgical Critical Care, Section of Anaesthesia and Intensive Care, Florence University, Italy; Tel: +39 055 7949664;

E-mail: lfabbri@unifi.it, 1.fabbri@dfc.unifi.it
}

suppressive (IL-10) properties [5,6]. Factors like type of pathogen, size of bacterial inoculum, site of infection, type of APC influence T effector cells towards a polarized Th1or a Th2 profile. Patients with sepsis have features of a Th1oriented response with the production of high levels of proinflammatory cytokines, initially. However, if sepsis persists, there would be a shift towards an anti-inflammatory immunosuppressive state, characterised by anergy of effector $\mathrm{T}$ cells (loss of costimulatory and MHC class II molecules by APC), increased apoptosis of $\mathrm{T}$ and $\mathrm{B}$ cells as well as a switch from a protective Th1- to a less protective Th2 profile of immune response $[7,8]$. Septic patients with burns or trauma are shown to display reduced levels of Th1 cytokines and an increase of serum IL-4 and IL-10 and reversal of Th2 cytokines improve their survival [9]. To identify Th2 cells in human circulation, a CRTh2 (chemoattractant receptor - homologous molecule expressed on Th2 cells) has been considered to be a reliable tool both in health state and in disease conditions $[10,11]$. However, the reliability of such a parameter to identify the state of Th2 in sepsis, in an attempt to foresee patient prognosis, was barely tackled, so far [12]. Therefore, the study of this immune response parameter and the role of immunosuppression in the prognosis of septic patients still need to be explored. Moreover, total IgE serum levels, which are usually considered as a surrogate marker of Th2 response, as well as the serum levels of type 1 and type 2 associated chemokines have been analysed. 
Therefore, this study was addressed to evaluate the prognostic value of the abovementioned old and new Th2 markers during the clinical course of sepsis.

\section{MATERIALS AND METHODOLOGY}

Study population. Critically ill patients, aged between 40 and 80 years, were consecutively included in this prospective study between January 2004 and December 2006. The enrolled patients had developed a state of severe sepsis/septic shock for more than 48 hours, as defined by the ACCP/SCCM Consensus Conference [13]. A written informed consent was obtained from patients or their relatives. Pregnant women, transplanted patients, patients with cancer, viral hepatitis, known history of allergy, or acquired immunodeficiency syndrome, and patients with uncontrolled bleeding, or under chemotherapy, radiotherapy, hemofiltration, or steroidal/non-steroidal anti-inflammatory agents were excluded. Mortality was defined as death occurring within 28 days after the diagnosis. This study has been carried out according to the ethical standards of the responsible regional Committee on human experimentation and to the Helsinki Declaration principles [14].

Study design. Blood samples were collected at the time of their enrolment and thereafter at the $5^{\text {th, }}$ and $10^{\text {th }}$ day. Sequential Organ Failure Assessment (SOFA) score was used for the daily assessment of patients' disease severity state [15]. 30 age-matched healthy non-allergic volunteers were enrolled as control group to establish the "reference values" for the methods used. The blood samples were collected through an indwelling catheter in tubes containing EDTA, maintained at $20^{\circ} \mathrm{C}$, and analyzed within $6 \mathrm{~h}$. The evaluations of sepsis and organ dysfunctions were prospectively done by investigators blinded to the assay results.

Flow Cytometry. FITC-, PE- or APC-conjugated mAbs for $\mathrm{CD} 3, \mathrm{CD} 4, \mathrm{CD} 8$, molecules were purchased from Becton Dickinson (San Jose, CA). anti-CRTH2 mAb was kindly provided by Nagata K. (R \& D Center, BML, Inc., Matoba, Kawagoe, Saitama, Japan).

Flow cytometry analysis [16] of cell suspensions was performed on blood samples by a FACSCanto cytofluorimeter using the CellQuest software (Becton Dickinson, San Diego, CA). Absolute number of each lymphocyte subset was automatically calculated, based on the absolute values of lymphocytes detected by CD45+cells count in the total white cells.

Detection Of Serum Chemokines. The serum concentration of CCL22 (MDC), CXCL10 (IP-10), CXCL12 (SDF1), CCL3 (MIP1a), CCL4 (MIP1b), and CCL5 (RANTES) were evaluated by commercial kits (R\&D systems, CA) according to the manufacturer's instructions.

Detection Of IgE Antibody. Total IgE serum concentration and $\mathrm{Ca}$-specific $\operatorname{IgE~Ab}$ were evaluated by commercial kits (IgE CapSystems, Pharmacia, Uppsala, Sweden).

\section{Statistical Analysis}

Data are expressed as mean \pm standard deviation of the mean (SD), and categorical data as median (range). Continuous parametric data were analysed using one-way ANOVA with Bonferroni post-hoc t-test for repeated measurement comparisons. Non parametric data were analyzed using the Kruskal-Wallis test. Correlation between parameters was analyzed using the Spearmann rank correlation test. A value of $p<0.05$ was considered statistically significant. Statistical analysis was performed with STATA software 8.0 for Windows (Stata Corporation, College Station, USA).

\section{RESULTS}

30 patients were consecutively enrolled during the study period. Patients' characteristics are shown in Table 1. The mean age for the control group was $65.4 \pm 9.8$.

\section{Increased Th2-Related Serum Markers Correlate with Poor Prognosis in Septic Patients}

The mean value (+ SEM) of total $\operatorname{IgE~Ab}$ in the sera of septic patients $(134.6+35.7 \mathrm{IU} / \mathrm{ml})$ was significantly $(p<0.01)$ higher than those of control group $(19+13 \mathrm{IU} / \mathrm{ml})$. Interestingly, total $\mathrm{IgE}$ concentration at the admission to ICU of subjects who died $(165.3+64.5 \mathrm{IU} / \mathrm{ml})$ were higher than those of survived patients $(60.1+32.6 \mathrm{IU} / \mathrm{ml})(\mathrm{p}<0.05)$. Accordingly and more importantly, a significant correlation $(p<0.01)$ was found between IgE serum concentration and the corresponding SOFA score at different time-points of the disease (Fig. 1).

Successively, we assessed the correlations between the serum concentration of chemokines associated to type 1 (CXCL10, CCL3, CCL4, CCL5) and type 2 (CXCL12, CCL22) $T$ cell responses and SOFA score at different timepoints of the disease. Interestingly, whereas no correlation among CXCL10 $(\mathrm{r}=0,14), \quad$ CXCL12 $(\mathrm{r}=0,10), \quad$ CCL3 $(\mathrm{r}=0,11)$, CCL4 $(\mathrm{r}=0,02)$, CCL22 $(\mathrm{r}=0,12)$ and SOFA score was found, the serum concentration of CCL5/RANTES (a CCR5-ligand, related to Th1 response) were significantly $(p<0.01)$ inversely related to SOFA score (Fig. 2 ).

\section{Increased Th2 Cells Correlate with a Poor Prognostic Value in Septic Patients}

In order to evaluate the role of functional $\mathrm{T}$ cell subsets during different time-points of sepsis, peripheral blood mononuclear cell (PBMC) from septic patients were analysed for the percentages and the absolute values of CD3+CD4+, CD3+CD8+, or CRTH2 (Th2 cells).

A significant $(p<0,01)$ direct correlation between the percentages of $\mathrm{CD} 4+\mathrm{CRTH} 2+\mathrm{T}$ cells and SOFA score at different time points was observed (Fig. 3A,B). Of note, an inverse correlation between the percentages of $\mathrm{CD} 4+\mathrm{CRTH} 2+\mathrm{T}$ cells and circulating leukocytes $(\mathrm{r}=-0.39$, $\mathrm{p}<0.01)$ and between CD4+CRTH2+ T cells and CCL5 serum levels $(r=-0.59, p<0.01)$ was also seen (data not shown).

\section{DISCUSSION}

The type of immune response during sepsis is determined by factors like pathogens virulence, size of inoculum, patient's conditions, the initial disease, and, finally, the polymorphisms of cytokine genes or other immune effector molecules and their receptors. There is a general consensus that initial immune response in sepsis is characterized by the hyper-expression of proinflammatory mediators, even though it may rapidly progress to a state of hypoinflammation prevalently due to the downregulation of the 
Table 1. Patients' Characteristics

\begin{tabular}{|c|c|c|c|c|c|c|c|}
\hline Pts & Age (Years) & Gender & Infection Source & ACCP/SCCM Diagnosis & SOFA Score & Blood Cultures & Outcome \\
\hline $\mathbf{L P}$ & 44 & $\mathrm{~F}$ & Pneumonia & Septic shock & $11 / 7 / 4$ & Staph. NMRSA & Survived \\
\hline MG & 60 & M & Peritonitis & Severe sepsis & $13 / 8 / 13$ & Enteroc. faecalis & - \\
\hline ML & 77 & M & Cellulitis & Severe sepsis & $7 / 15 / 4$ & Staph. epidermidis & survived \\
\hline SG & 64 & M & Pneumonia & Septic shock & $14 / 13 / 13$ & Sterile & - \\
\hline ST & 76 & $\mathrm{~F}$ & Peritonitis & Severe sepsis & $5 / 9 / 15$ & Sterile & - \\
\hline PU & 76 & $\mathrm{~F}$ & Cholecystitis & Severe sepsis & $8 / 13 / 16$ & Sterile & - \\
\hline LE & 50 & M & Peritonitis & Severe sepsis & $8 / 4 / 1$ & Esch. coli & survived \\
\hline FC & 82 & $\mathrm{~F}$ & Peritonitis & Septic shock & $8 / 11 / 15$ & Staph. MRSA & - \\
\hline $\mathbf{C R}$ & 68 & M & Pneumonia & Severe sepsis & $8 / 12 / 15$ & Candida (BAL) & - \\
\hline BP & 58 & M & Pneumonia & Severe sepsis & $6 / 12 / 15$ & staph. MRSA & - \\
\hline ML & 74 & M & Pneumonia & Septic shock & $7 / 4 / 1$ & Sterile & survived \\
\hline DA & 60 & $\mathrm{~F}$ & Lung abscess & Severe sepsis & $11 / 6 / 3$ & Pseudom. (BAL) & survived \\
\hline NM & 37 & M & Peritonitis & Severe sepsis & $6 / 2 / 1$ & Sterile & survived \\
\hline $\mathbf{L F}$ & 46 & $\mathrm{~F}$ & Cellulitis & Severe sepsis & $6 / 10 / 10$ & Sterile & - \\
\hline $\mathbf{L C}$ & 62 & M & Pneumonia & Septic shock & $10 / 12 / 12$ & Acitenobacter (BAL) & - \\
\hline PP & 74 & $\mathrm{~F}$ & Lung abscess & Septic shock & $12 / 10 / 8$ & Staph. MRSA & survived \\
\hline MA & 63 & $\mathrm{~F}$ & Peritonitis & Severe sepsis & $10 / 14 / 13$ & Sterile & - \\
\hline MN & 55 & M & Peritonitis & Septic shock & $8 / 4 / 4$ & Sterile & survived \\
\hline CB & 80 & $\mathrm{~F}$ & Pneumonia & Severe sepsis & $6 / 4 / 2$ & Sterile & survived \\
\hline SB & 52 & $\mathrm{~F}$ & Pneumonia & Severe sepsis & $8 / 10 / 10$ & Sterile & - \\
\hline MM & 82 & M & Peritonitis & Severe sepsis & $4 / 6 / 5$ & Enteroc. faecium & survived \\
\hline PL & 68 & $\mathrm{~F}$ & Peritonitis & Septic shock & $10 / 8 / 6$ & Sterile & survived \\
\hline PA & 58 & M & Pneumonia & Severe sepsis & $6 / 8 / 6$ & Sterile & survived \\
\hline $\mathbf{L L}$ & 63 & M & Pneumonia & Severe sepsis & $8 / 12 / 12$ & Staph. VREF & - \\
\hline GB & 60 & M & Peritonitis & Septic shock & $6 / 10 / 10$ & Esc. coli (peritoneal fluid) & - \\
\hline MG & 41 & M & Pneumonia & Severe sepsis & $6 / 5 / 5$ & Staph. MRSA & survived \\
\hline MF & 67 & M & Pneumonia & Severe sepsis & $5 / 6 / 4$ & Sterile & survived \\
\hline TC & 58 & $\mathrm{~F}$ & Pneumonia & Septic shock & $14 / 14 / 14$ & Sterile & - \\
\hline MC & 79 & M & Peritonitis & Severe sepsis & $10 / 8 / 8$ & Enterc. faecalis & survived \\
\hline GN & 72 & M & Peritonitis & Severe sepsis & $12 / 8 / 4$ & Sterile & survived \\
\hline $\begin{array}{l}\text { Mean } \pm \\
\text { SD }\end{array}$ & $63,5 \pm 12$ & $\begin{array}{l}\mathrm{M} / \mathrm{F}: \\
18 / 12\end{array}$ & & & & & $\begin{array}{c}\text { mortality } \\
46,8 \%\end{array}$ \\
\hline
\end{tabular}

Pts: patients, F female, M male; SD: standard deviation, NMRSA: non methicillin-resistant Staphylococcus aureus MRSA: methicillin-resistant Staphylococcus aureus; VREF: Vancomycin resistant staphylococcus

major protective mechanisms. Indeed a shift to a less protective $\mathrm{T}$ (namely Th2 cells) cells secreting anti-inflammatory cytokines have been described to be relevant for a poor prognosis [7, 17]. Even though timing of these alterations are not fixed and the involved mechanisms may be different in each patient, however measurement of circulating inflammatory mediators may prove to be useful in evaluating the stage of sepsis and in adopting the most appropriate treatment [18].
Aim of this study was to evaluate the prognostic value of old and new Th2 cell markers and to analyse their relationship with the clinical outcome of severe sepsis.

We initially examined the total IgE serum levels which are usually considered as a surrogate marker of $\mathrm{Th} 2$ response since the type 2 cytokines (such as IL-4 and IL-13) are the major switching factors for $\varepsilon$ isotype. Total $\operatorname{IgE}$ levels in the sera of septic patients were significantly higher than those of the control group. In addition, total IgE levels, measured at 


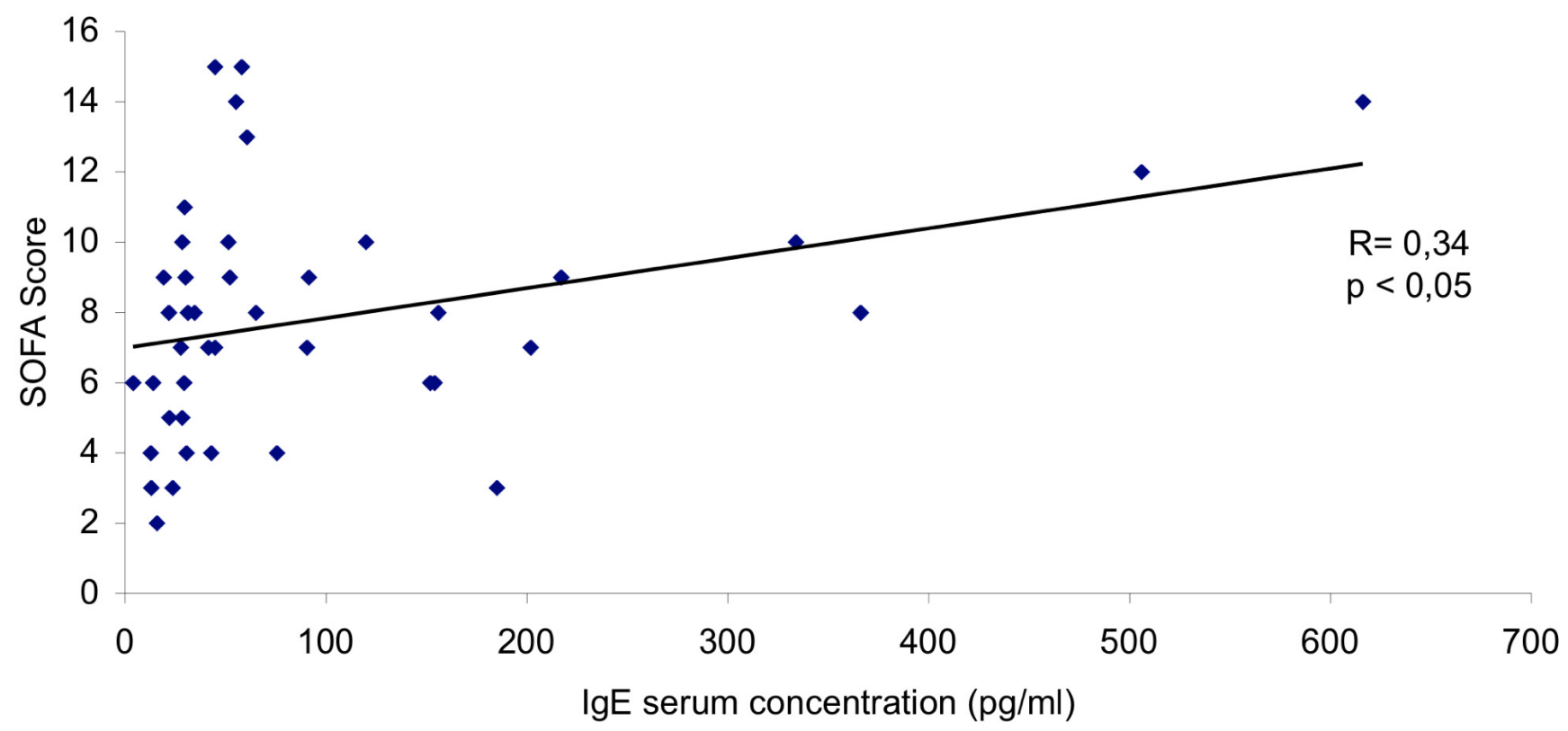

Fig. (1). Correlation between SOFA score and total IgE serum levels ( $R$ 0.34; $p<0.05)$.

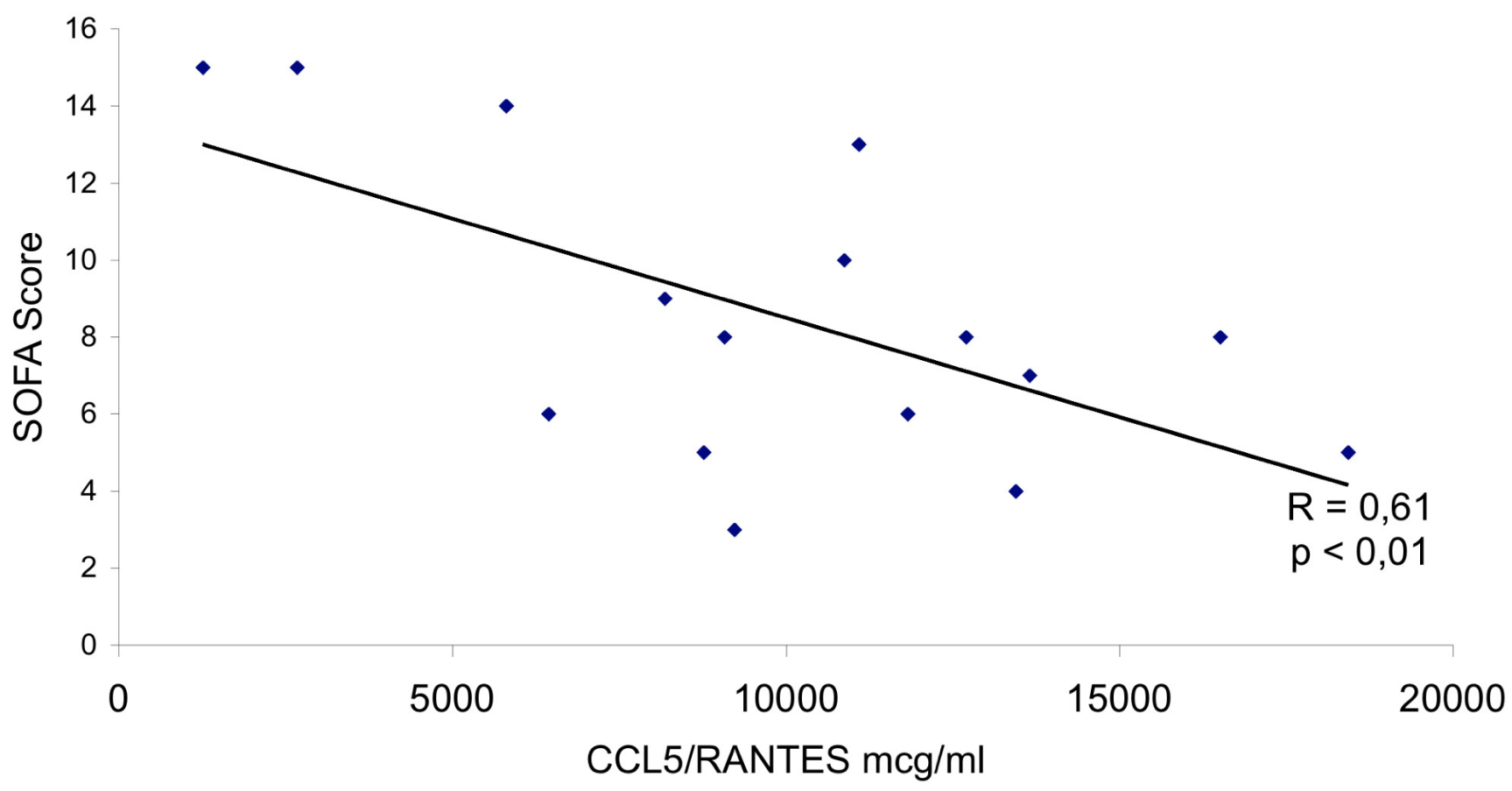

Fig. (2). Correlation between SOFA score and serum levels of CCL5/RANTES (R-0.61; $<<0.01)$.

the enrolment in the study, of subjects who died were higher than those of survived patients. More importantly, IgE serum levels were correlated to the corresponding SOFA scores at different time-points of the disease. All these findings suggest that a Th2-oriented response is frequently observed in septic patients and that it correlates with a poor prognosis. Even though the increased IgE serum levels and hypereosinophilia have been found associated with sepsis in traumatic patients $[19,20]$, this parameter has not been extensively evaluated in the majority of studies on septic patients.

Thereafter, the serum levels of type1- (CXCL10, CCL3, CCL4 and CCL5) or type 2-(CXCL12, CCL22) associated chemokines (prevalently recruiting CXCR3+CCR5+Th1- or
CXCR4+CCR4+ Th2 cells) have been analysed. Interestingly, we observed that the serum levels of CCL5/RANTES (one of the ligands for CCR5+Th1 cells) were inversely related to SOFA score. A decreased CCL5 level has been shown in umbilical serum of preterm neonates with pneumonia or sepsis [21] and it has been associated with mortality in children with cerebral malaria [22]. Also the early effect of a systemic administration (in bolus) of endotoxin in healthy volunteers revealed a significant impairment of CCL5 serum levels [23].

Based on these previous studies, our result acquires a stronger relevance since, for the first time, it defines an in- 
(A)

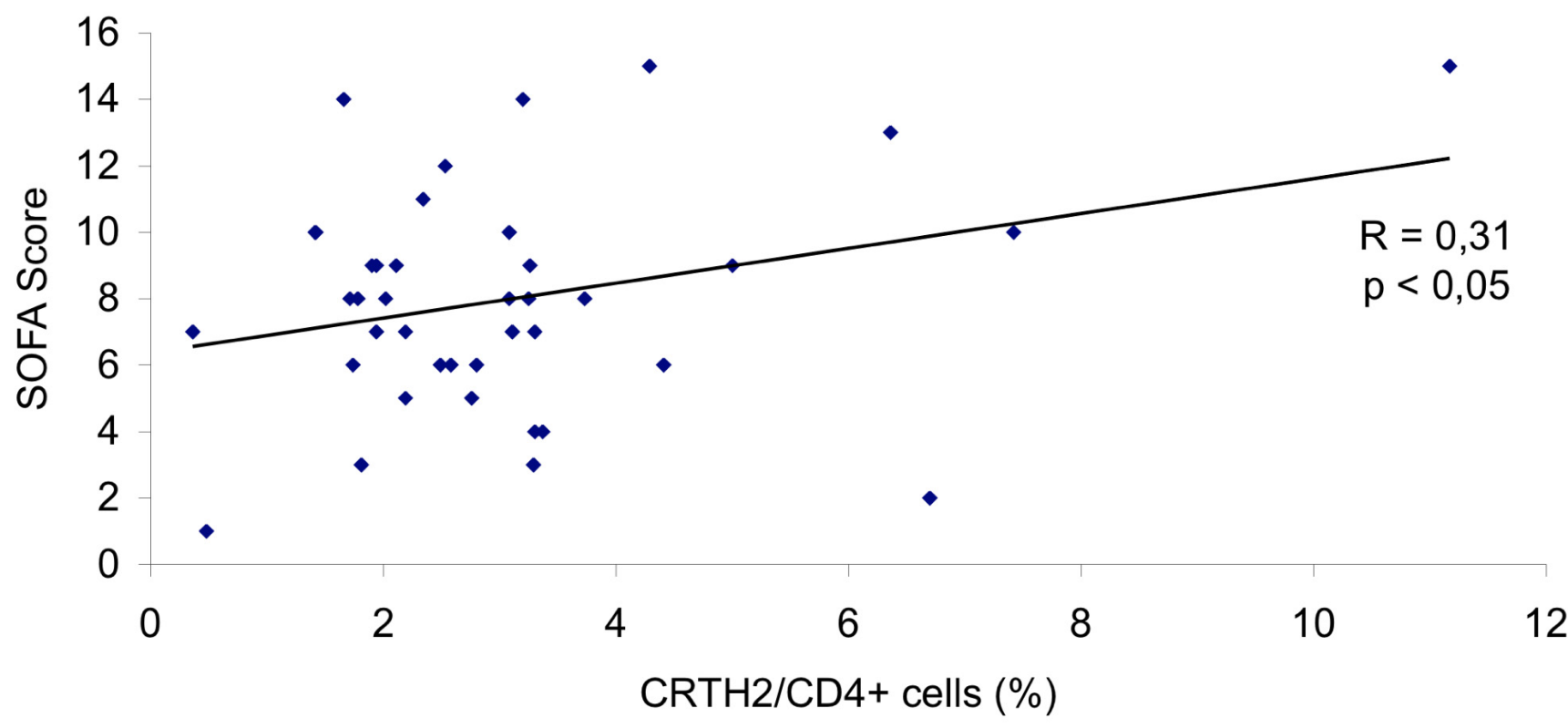

(B)

\section{$\mathrm{CD}^{4+}$ gated}

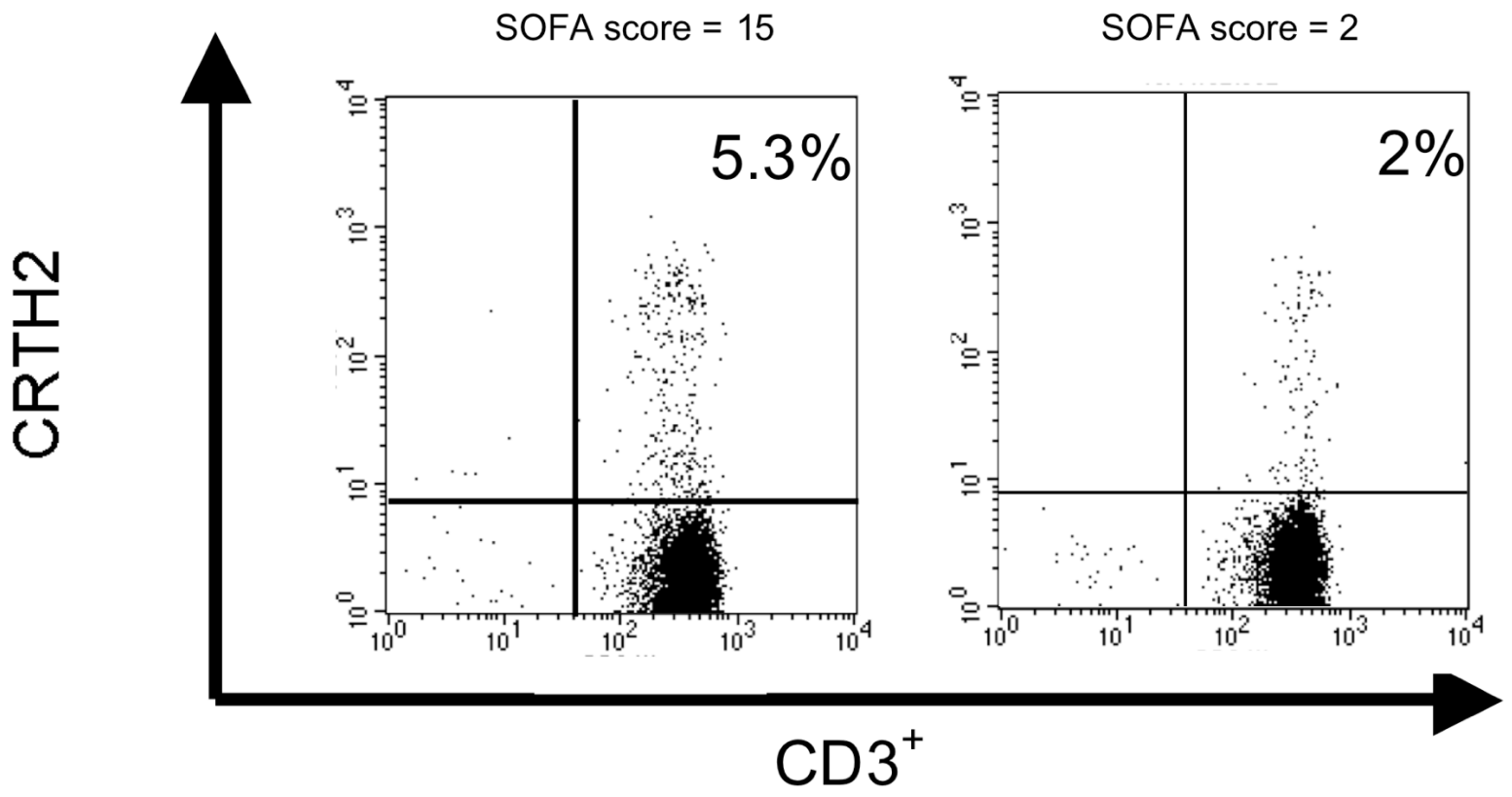

Fig. (3). Correlation between CRTh2 expression and SOFA score (R0.31; $<<0.05)$. (A) CRTh2 expression on CD4+ gated T cells was evaluated by flow cytometry. (B) Representative experiment of CRTh2 expression by CD4+CD3+ T lymphocytes as detected by flow cytometry in two patients showing high (left panel) or low (right panel) SOFA score.

verse correlation between a clinical index and a Th1associated chemokines in septic patients.

In this contest the absence of any correlation with other type 1- or type 2-chemokines is intriguing and difficult to explain. It certainly reflects the complexity of mechanisms underlying the immune response, elicited also in the same phase of sepsis, which in turn may influence and annul each other.

Lastly, our study has been addressed to define possible correlations among clinical indexes and circulating Th2 cells which may condition the protection against infections.

As regards the circulating Th2 cells in septic patients, a chemokine receptor has been recently described on such cell 
subset. Such a molecule, which is called chemoattractant receptor for Th2 cells (CRTH2) [24], is also expressed by eosinophils and basophils. We have shown that CRTH2 is the only molecule among those described, so far, which was selectively expressed by Th2 and type 2 cytotoxic CD $8+\mathrm{T}$ cells (Tc2) in vitro and by circulating Th2 and Tc2 cells in vivo, whereas it was never detectable on Th1, Tc1, type 0 Th (Th0) or type $0 \mathrm{Tc}(\mathrm{Tc} 0)$ cells [11]. The ligand for CRTH2 is produced by mast cells and has recently been identified as prostaglandin D2 [24,25]. The results of this paper clearly show a high correlation between the percentages of circulating $\mathrm{CRTH} 2+\mathrm{CD} 4+\mathrm{T}$ cells and the clinical course. This suggests that the clinical worsening of septic patients is often induced and maintained by the specific shift towards a predominant Th2 phenotype. This result is in agreement with previous published data indicating a lower Th1/Th2 ratio of cytokine-producing T cells (or an increased IL-4-producing CD4+ T cells) in PBMC of septic or polytraumatic patients $[8,17]$. On the other hand, it has been shown that in the murine model of sepsis obtained with the cecal ligation and puncture, the release of IL-4 was markedly increased and the IL-4-induced activation of the STAT6 pathway contributed to the immunosuppression and death in sepsis [26]. By contrast the in vivo treatment with neutralising anti-IL-4 Ab markedly increased the survival rates in septic animals [26].

In addition, there are clearcut evidences showing that the cytokines IL-17A/F are crossregulated by IL-4 in vitro and in vivo models $[27,28]$. Furthermore, it has been shown that a novel subset of $\mathrm{T}$ cells producing these cytokines (now called Th17) is associated to chronic inflammation sustained by neutrophil infiltration since IL-17A/F triggers several inflammatory cells to secrete pro-inflammatory molecules (as CCL5) and neutrophil chemoattractants [29,30]. In this contest it is relevant that the percentages of CRTH $2+\mathrm{CD} 4+$ $\mathrm{T}$ cells of our septic patients are inversely correlated to both CCL5 serum levels and to total circulating leukocytes.

\section{CONCLUSION}

On the whole, these data suggest that the correlations between the clinical course of sepsis versus total IgE levels (direct), CCL5 serum levels (inverse) and the percentages of circulating $\mathrm{CRTH} 2+\mathrm{CD} 4+\mathrm{T}$ cells (direct) confirm that the clinical worsening in septic patients may be linked to a Th2 shift of immune responses. Since several other (immunologic and non immunologic) mechanisms may contemporarily operate in these patients, it is likely that the Th2 shift can be evident at the tissue but not always at the systemic level. Although these results need to be validated on a more large scale of population, the longitudinal analysis of all these parameters during the disease course may be considered as an useful prognostic tool in sepsis.

\section{ACKNOWLEDGEMENTS}

Preliminary results of this work have been presented at the WCA, Paris 2004.

The paper was supported by grants in part from Istituto Superiore di Sanita' (AIDS program), Associazione Italiana per la Ricerca sul Cancro (AIRC) and Ministery Of University and Scientific Research, Italy.

\section{REFERENCES}

[1] Mackenzie I, Lever A. Management of sepsis. BMJ 2007; 335 : 929-32.

[2] Angus, DC, Linde-Zwirble WT, Lidicker J, Clermont G, Carcillo J, Pinsky MR. Epidemiology of severe sepsis in the United States: analysis of incidence, outcome, and associated costs of care. Crit Care Med 2001; 29: 1303-1310.

[3] Riedemann NC, Guo RF, Ward PA. A key role of C5a/C5aR activation for the development of sepsis. J Leukoc Biol 2004; 74: 96670.

[4] Van Amersfoort ES, Van Berkel TJ, Kuiper J. Receptors, mediators, and mechanisms involved in bacterial sepsis and septic shock. Clin Microbiol Rev 2003; 16: 379-414.

[5] Romagnani S. Lymphokine production by human $\mathrm{T}$ cells in disease states. Annu Rev Immunol 1994; 12: 227-57.

[6] Abbas AK, Murphy KM, Sher A. Functional diversity of helper T lymphocytes. Nature 1996; 383: 787-93.

[7] Hotchkiss RS, Karl IE. The pathophysiology and treatment of sepsis. N Engl J Med 2003; 348: 138-50.

[8] Ferguson NR, Galley HF, Webster NR. T helper cell subset ratios in patients with severe sepsis. Int Care Med 1999; 25: 106-109.

[9] Lederer JA, Rodrick ML, Mannick JA. The effects of injury on the adaptive immune response. Shock 1999; 11: 153-9.

[10] Nagata K, Tanaka K, Ogawa K, et al. Selective expression of a novel surface molecule by human Th2 cells in vivo. J Immunol 1999; 162: 1278-1286.

[11] Cosmi L, Annunziato A, Galli MIG, Maggi E, Nagata K, Romagnani S. CRTH2 is the most reliable marker for the detection of circulating human type $2 \mathrm{Th}$ and type $2 \mathrm{~T}$ cytotoxic cells in health and disease. Eur J Immunol 2000; 30: 2972-2979.

[12] Venet F, Lepape A, Debard AL, Bienvenu J, Bohe' J, Monneret G. The Th2 response as monitored by CRTH2 or CCR3 expression is severely decreased during septic shock. Clin Immunol 2004; 113: 278-284.

[13] Levy MM, Fink MP, Marshall JC, et al. SCCM/ESICM/ACCP/ ATS/SIS. 2001 SCCM/ESICM/ACCP/ATS/SIS International Sepsis Definitions Conference. Crit Care Med 2003; 31: 1250-6.

[14] World Medical Association. Ethical principles for medical research involving human subjects. Eur J Emerg Med 2001; 8: 221-224.

[15] Peres Bota D, Melot C, Lopes Ferreira F, Nguyen Ba V, Vincent JL. The Multiple Organ Dysfunction Score (MODS) versus the Sequential Organ Failure Assessment (SOFA) score in outcome prediction. Int Care Med 2002; 28: 1619-1624.

[16] Cosmi L, Santarlasci V, Angeli R, et al. Sublingual immunotherapy with Dermatophagoides monomeric allergoid down-regulates allergen-specific immunoglobulin $\mathrm{E}$ and increases both interferon $-\gamma$ and interleukin -10- production. Clin Exp All 2006; 36: 261-272.

[17] Spolarics Z, Siddiqi M, Siegel JH, et al. Depressed interleukin-12producing activity by monocytes correlates with adverse clinical course and a shift toward Th2-type lymphocyte pattern in severely injured male trauma patients. Crit Care Med 2003; 31: 1722-1729.

[18] Oberholzer A, Steckholzer U, Kurimoto M, Trentz O, Ertel W. Interleukin-18 plasma levels are increased in patients with sepsis compared to severely injured patients. Shock 2001; 16: 411-4.

[19] DiPiro JT, Howdieshell TR, Hamilton RG, Adkinson NF Jr, Mansberger AR Jr. Increased plasma IgE levels in patients with sepsis after traumatic injury. J Allergy Clin Immunol 1996; 97: 135-6.

[20] DiPiro JT, Howdieshell TR, Hamilton RG, Mansberger AR Jr. Immunoglobulin $\mathrm{E}$ and eosinophil counts are increased after sepsis in trauma patients. Crit Care Med 1998; 26: 465-9.

[21] Krolak-Olejnik B, Beck B, Olejnik I. Umbilical serum concentrations of chemokines (RANTES and MGSA/GRO-alpha) in preterm and term neonates. Pediatr Int 2006; 48: 586-90.

[22] John CC, Opika-Opoka R, Byarugaba J, Idro R, Boivin MJ. Low levels of RANTES are associated with mortality in children with cerebral malaria. J Infect Dis 2006; 194: 837-45.

[23] Schinkel S, Schinkel C, Pollard V, et al. Effects of endotoxin on serum chemokines in man. Eur J Med Res 2005; 10: 76-80.

[24] Nagata K, Hirai H, Tanaka K, et al. CRTH2, an orphan receptor of T-helper-2-cells, is expressed on basophils and eosinophils and responds to mast cell-derived factor(s). FEBS Lett 1999; 459: 195-9. 
[25] Hirai H, Tanaka K, Yoshie O, et al. Prostaglandin D2 selectively induces chemotaxis in T helper type 2 cells, eosinophils, and basophils via seven-transmembrane receptor CRTH2. J Exp Med 2001; 193: 255-61.

[26] Song GY, Chung CS, Chaudry IH, Ayala A. IL-4-induced activation of the Stat6 pathway contributes to the suppression of cellmediated immunity and death in sepsis. Surgery 2000;128: 133-8.

[27] Schnyder-Candrian S, Togbe D, Couillin I, et al. Interleukin-17 is a negative regulator of established allergic asthma. J Exp Med 2006; 203: $2715-25$.
[28] Iwakura Y, Ishigame H. The IL-23/IL-17 axis in inflammation. J Clin Invest 2006; 116: 1218-22.

[29] Bettelli E, Kuchroo VK. IL-12- and IL-23-induced T helper cell subsets: birds of the same feather flock together. J Exp Med 2005; 201: 169-71.

[30] Park H, Li Z, Yang XO, et al. A distinct lineage of CD4 T cells regulates tissue inflammation by producing interleukin 17 . Nat Immunol 2005; 6: 1133-41.

(C) Fabbri et al.; Licensee Bentham Open.

This is an open access article distributed under the terms of the Creative Commons Attribution License (http://creativecommons.org/license/by/2.5/), which permits unrestrictive use, distribution, and reproduction in any medium, provided the original work is properly cited. 